\title{
Retraction Notice: J. Golini, Improved Creatine Stability and pH Profile for Kre-Alkalyn, International Journal of Pharmacology, Phytochemistry and Ethnomedicine, Vol. 1, pp. 20-22, 2015 \\ Editorial office of International Journal of Pharmacology, Phytochemistry and Ethnomedicine
}

\author{
Seestrasse 24c, CH-8806 Bach, Switzerland \\ ijppe@scipress.com
}

This article has been retracted at the request of a Publisher's representative.

The article [1] has been proven to be a duplicate of the publication [2].

The manuscript was submitted to the Journal of Biosensors \& Bioelectronics (JBB) three months prior to the date of submission to the International Journal of Pharmacology, Phytochemistry and Ethnomedicine (IJJPE) and nearly in two weeks after its submission to IJPPE it was published online in JBB. Duplicate publication of any form is considered to be a publication malpractice. Thus, the article was subjected to retraction for the purpose of eliminating the duplicate publication in line with the Retraction Guidelines of the Committee on Publication Ethics.

The author of [1] has been informed about the decision to retract the article [1]. He stated that he is not aware of the circumstances that led to the redundant publication and agreed to the retraction. Thus, the paper has been declared retracted and marked accordingly.

\section{References}

[1] J. Golini, Improved creatine stability and $\mathrm{pH}$ profile for Kre-Alkalyn, International Journal of Pharmacology, Phytochemistry and Ethnomedicine. 1 (2015) 20-22. DOI: 10.18052/www.scipress.com/IJPPE.1.20.

[2] J. Golini, Improved creatine stability and pH Profile for Kre-Alkalyn, Journal of Biosensors \& Bioelectronics. 6(4) (2015) 1-2. DOI: 10.4172/2155-6210.1000187. 